\title{
Factors to improve the efficiency of a vertical screw mixer of bulk materials
}

\author{
Roman Cherkasov ${ }^{1}$, Kasyan Adigamov ${ }^{1, *}$, Victor Pershin ${ }^{1}$, Arkady Cherepenko ${ }^{2}$ \\ ${ }^{1}$ Institute of service sector and entrepreneurship (branch) of Don State Technical University, Russian \\ Federation \\ ${ }^{2}$ Orel State University named after I.S. Turgenev, Russian Federation
}

\begin{abstract}
The paper shows that it is possible to increase the efficiency of a vertical screw mixer of bulk materials and reduce costs by determining the required size of the feeding hole in the lower part of the casing, as well as by installing a screw flange with a reverse winding in relation to the screw spiral inside the screw casing and by installing a replaceable tip with a variable lead angle at the lower end of the screw. The analysis of the process of screw loading in the hopper allowed us to obtain an analytical dependence to determine the required size of the feeding hole, in which mixed materials freely enter the screw spiral. It is proved that the placement of the screw flange on the inner surface of the casing increases the driving force of material by $1.05-1.80$ times depending on the screw speed, which significantly reduces specific energy consumption for preparation of mixture of the desired quality. The paper provides the formula for calculating the angle of installation of the flange with respect to the screw spiral, in which the maximum effect of the flange on the mixed materials is obtained. In order to ensure the effective capture of mixed materials in the loading zone of the screw, it is proposed to perform the first spiral turn from the lower end of the screw with a variable lead angle and place it on a replaceable tip. A technical solution to the placement of spirals on the double-threaded screw is also proposed.
\end{abstract}

\section{Introduction}

For effective implementation of bulk materials mixing process, it is necessary to have equipment that fully meets the resource saving requirements while ensuring the required quality of products.

\section{Materials and Methods}

We consider the process of mixing bulk materials on the example of the screw mixer (Fig. 1), the schematic diagram of which is developed based on the analysis of the designs of known mixers and for which patents for utility models are issued $[1,2,3]$.

\footnotetext{
*Corresponding author: adigamov_k@mail.ru
} 


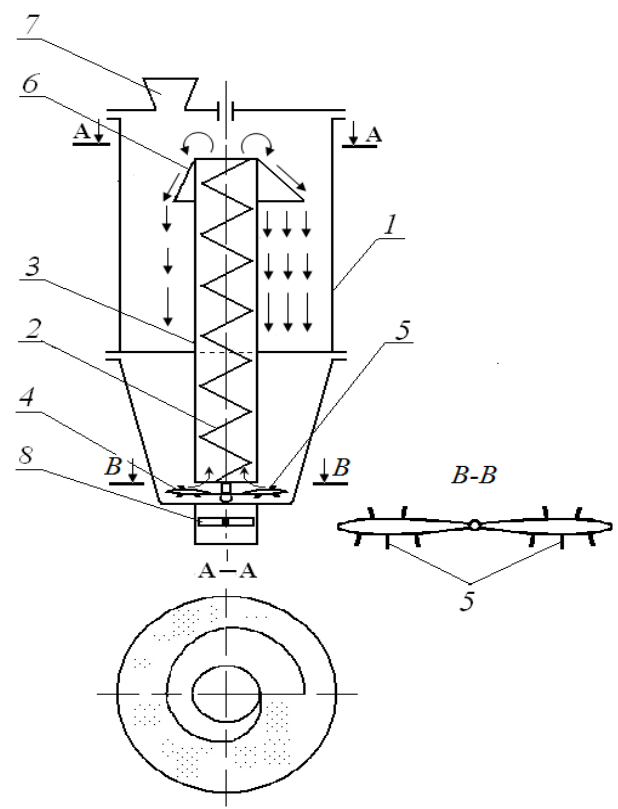

Fig. 1. Screw mixer.

The screw mixer consists of a hopper 1 of a cylindrical-conical shape, a screw 2 and a casing 3. The lower end of the screw is attached to the blade 4, rotating together with the screw 2. At the top end of the casing 3 is a conical diffuser 6 of a variable radius. The hopper 1 is feeded through the feed nozzle 7 , the mixture is discharged through the valve 8 .

The mixing process is as follows. First, the mixture components are loaded into the hopper 1 via the receiver 7 . Then the screw drive 2 is turned on (not shown in the diagram) and the blade 4 feeds materials to the screw, which captures the mixture and moves it along the inner cavity of the casing to the upper end, where it falls on the diffuser 6 and from there falls down the entire cross-sectional area of the hopper, where it is again captured by the screw, moves up and falls down again, thereby circulating the mixed materials. The blade has 4 cutting elements 5 , which can destroy clumps of matted or compacted material.

Analyzing the operation of this mixer, it is possible to distinguish three areas in which materials mixing occur [4]:

area, where material is captured by the screw at the bottom of the hopper;

area, where material is handled by the screw inside the casing;

area, where material sheds from the conical diffuser.

In the first area, mixing occurs due to the fact that the screw 2, grabbing the material from the bottom of the hopper and moving it inside the casing 3, creates conditions for lowering the overlying layers inside the hopper down. In order for the materials to flow freely into the lower part of the hopper, it is necessary that the hopper element in its conical part is at the angle that allows the mixed materials to fall down by gravity. It is also necessary that the feeding holes at the bottom of the casing have such dimensions that provide an intensive supply of material to the screw $[5,6]$.

In the second area, when the materials are moved by the screw inside the casing, their mixing occurs under the influence of such factors as the design and operating parameters of the screw, determined taking into account physical and mechanical properties of the mixed materials.

In the third area, the mixing of materials occurs due to their shedding from the diffuser over the entire cross-sectional area of the hopper. 
Feeding holes should have a cross-sectional area, which in total is equal to the area of the useful cross-section of the screw space. A single-thread screw has one spiral and therefore such screw in one revolution has one capture of material. Multi-screw provides a number of captures equal to the number of spirals provided that there is a sufficient amount of material from the hopper, but such screws are rarely used due to the complexity of manufacturing, weighting and appreciation. Therefore, as a rule, single-thread screws are used [7].

Theoretically, in one revolution, a single-thread screw can place a volume of material equal to the volume of one turn on the spiral, which can be roughly determined from the expression:

$$
V_{B}=\frac{\pi}{4}\left(D^{2}-d^{2}\right)(h-6)
$$

where 8 - thickness of the spiral.

Vertical screw cannot work with a full load of turns due to the risk of stopping its work due to the material getting between adjacent turns of the spiral. Therefore, the formula (1) must be supplemented with a fill factor that cannot be equal to one.

$$
V_{B}=\frac{\pi}{4}\left(D^{2}-d^{2}\right)(h-6) \cdot k_{3}
$$

Therefore, through the feeding holes should go the amount of material equal to:

$$
V_{M}=V_{B}=S \cdot v
$$

where $S$ - the flow area of the feeding holes;

$v$ - the rate of receipt of mixed materials on the screw through the feeding holes.

Since loading of the vertical screw is made from a hopper, the lower part of which is a circular cone, it can be assumed that mixed materials come to the feeding holes of the screw casing by gravity. In it is shown that the speed of movement of bulk materials on an inclined plane can reach $1.5-2.0 \mathrm{~m} / \mathrm{s}$, and the angle of inclination of this plane should be greater than the angle of external friction by $5-10^{\circ}$.

From (2) and (3) we have:

$$
S=\frac{\pi}{4}\left(D^{2}-d^{2}\right)(h-6) \cdot k_{3} / u
$$

The expression (4) allows us to determine the required area of feeding holes in the screw casing with the known parameters of the screw.

The state of the inner surface of the casing has a significant impact on the rate of material advance along the vertical screw spiral. In order to reduce the frequency of rotation of the material together with the screw and to increase the rotation speed of the material in the direction of material lifting, it is proposed to install on the inner surface of the casing a screw flange with a reverse winding in relation to the screw spiral $[8,9,10,11]$. Fig. 2 shows the scheme of interaction of a material particle with a spiral and a flange. 


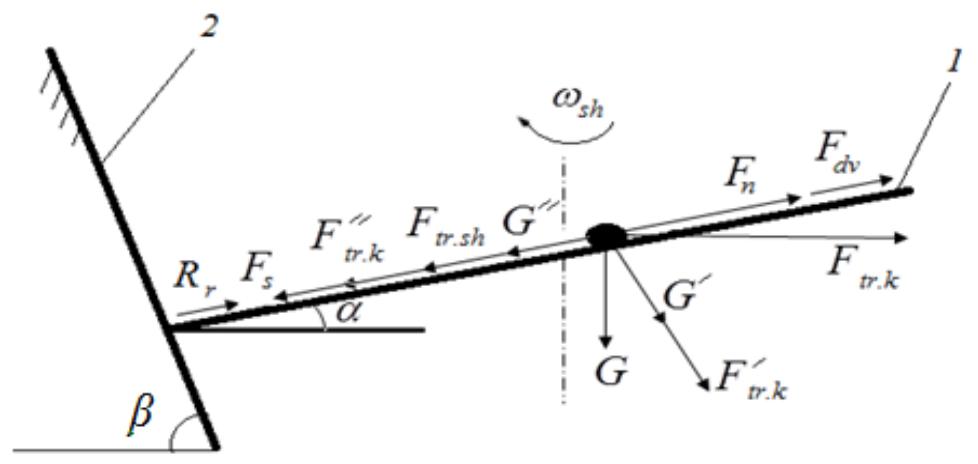

Fig. 2 Scheme of interaction of a material particle with a spiral and a flange: 1 - spiral, 2 - flange.

Using the screw with a smooth casing (without flange) the driving force of the material upward the spiral is:

$$
\mathrm{F}_{\mathrm{dv}}=, \mathrm{F}_{\mathrm{n}}-\mathrm{F}_{\mathrm{c}}
$$

where $\mathrm{F}_{\mathrm{n}}$ - lifting force;

$\mathrm{F}_{\mathrm{c}}$ - force of resistance to material movement.

$$
\mathrm{F}_{\mathrm{n}}=\mathrm{F}_{\text {tr.k }} \times \cos \alpha,
$$

where $\mathrm{F}_{\text {tr.k }}$ - friction force of the material against the screw casing;

$\alpha$ - lead angle of the screw spiral.

$$
\mathrm{F}_{\mathrm{c}}=\mathrm{G}^{\prime}+\mathrm{F}_{\text {tr.sh }}+\mathrm{F}_{\text {tr.k }},
$$

where G" - the component of the material weight force;

$\mathrm{F}_{\text {tr.sh }}$ - friction force of the material against the screw;

$\mathrm{F}_{\text {tr.k }}$ - the component of the friction force against the casing.

When working with a screw casing with a screw flange, the driving force is:

$$
\mathrm{F}_{\mathrm{dv}}=\mathrm{F}_{\mathrm{n}}+\mathrm{R}_{\mathrm{p}}
$$

where $R_{P}-$ is the reaction of the casing flange, which, as follows from the diagram in Fig. 2, equals to $F_{c}$. Hence,

$$
\mathrm{F}_{\mathrm{dv}}=\mathrm{F}_{\mathrm{n}}+\mathrm{F}_{\mathrm{c}} \text {, }
$$

Equation (9) differs from equation (5) in that, that the second term is not subtracted but summed. This is due to the fact that the flange repels a particle of material and thus contributes to its progress along the spiral, and the maximum impact of the flange will be if it is set perpendicular to the spiral. Hence the installation angle of the flange:

$$
\beta=90^{\circ}-\alpha
$$

\section{Results}

The results of a comparative calculation of the driving force using the screw with a smooth casing and a casing with a flange showed that the driving force when using a casing with a flange is greater in 1.05-1.80 times than when using a smooth casing [12,13].

Screws of a standard design, as a rule, are issued with a constant step of a spiral winding, i.e. with a constant lead angle of a spiral and therefore capture of material by a 
screw in the loading area can occur insufficiently effectively. Fig. 3 shows the scheme of interaction of the screw spiral 1 with the loaded material.

When the screw 1 rotates on the particle of the material 2, located on the spiral, there is the centrifugal force $F_{u}$, the component of which $F_{u}^{\prime \prime}=F_{u} \cdot \cos \alpha$ contributes to the introduction of the spiral into the material.

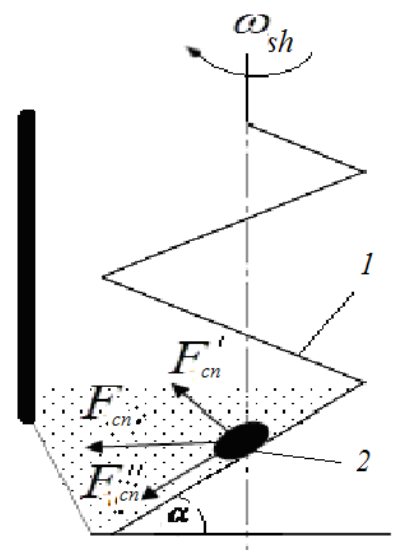

Fig. 3. Scheme of introduction of the spiral screw into the feed material.

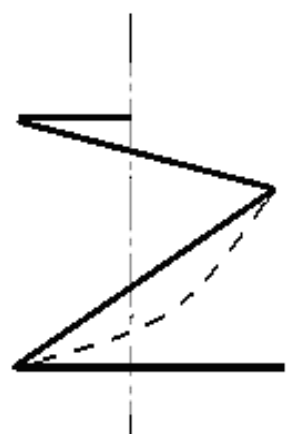

Fig. 4. Scheme of the spiral turn with a variable lead angle.

For successful screw loading it is necessary that $F_{u}^{\prime \prime}$ has the maximum value, and for this purpose it is necessary to reduce the angle $\alpha$. On the basis of this conclusion, it is proposed to perform the first turn from the lower end of the screw with a variable lead angle from zero at the beginning of the turn to the lead angle value at the rest of the screw at the end of the turn (Fig. 4), and to avoid difficulties in the manufacture of screws, it is proposed to produce this turn in the form of a replaceable tip with the possibility of its docking with the base screw.

With regard to the double-lead screws, it is proposed to install a replaceable tip with two spirals, each of which is made in the form of a blade with a variable lead angle, the initial edges of the tip spirals form an angle with the axis, the value of which can vary in the range from $16^{\circ} 42^{\prime}$ up to $26^{\circ} 36^{\prime}$ depending on the ratio of the diameter of the screw shaft to the outer diameter of the screw (Fig.5). A patent for the invention was granted for this technical solution [14]. 


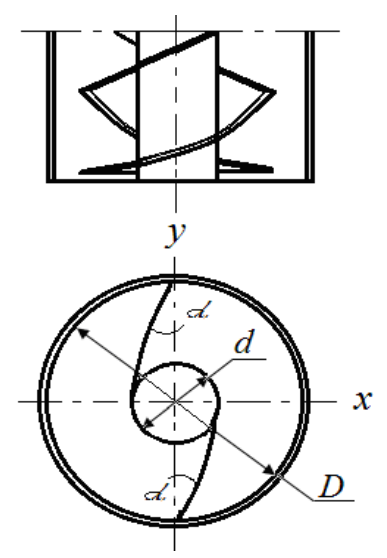

Fig. 5. Scheme of spirals arrangement on the tip.

\section{Discussion and Conclusion}

1. The performed studies have allowed us on the basis of studying the process of material movement by a vertical screw to establish that to intensify the process of components mixing inside the hopper, it is necessary to increase the speed of the material relative to the screw, which can be achieved by installing a screw flange on the inner surface of the casing.

2. Analytical dependences are obtained for determining the angle of the flange installation relative to the screw spiral and calculating the area of the feeding hole in the screw casing.

3. The original technical solutions that increase the efficiency of the vertical screw mixer of bulk materials are proposed.

\section{References}

1. S.S. Petrenko, G.V. Chernenko, S.N. Baybara, Screw mixer of bulk materials, Useful model patent $R F, 126624,2012145481$ (2013)

2. K.A. Adigamov, R.I. Cherkasov, S.N. Baybara, Screw mixer of bulk materials, Useful model patent $R F, 156670,2015110209 / 05$ (016094) (2015)

3. K.A. Adigamov, R.I. Cherkasov, S.N. Baybara, Screw mixer of bulk materials, Useful model patent $R F, 160268,2015144009 / 04$ (2016)

4. R.I. Cherkasov, Intensification of the process of mixing of bulk feed with a batch vertical screw mixer (Rostov-on-Don, 2017)

5. R.I. Cherkasov, Innovations in science 6(43), 60-68 (2015)

6. R.I. Cherkasov, N.A. Dmitrienko, Actual problems of modern science (Kiev, 2016)

7. K.A. Adigamov, G.V. Chernenko, Technical Sciences 3, 65-67 (2009)

8. K.A. Adigamov, G.V. Chernenko, A.V. Zelenschikov, Technical Sciences 3, 64-67 (2010)

9. K.A. Adigamov, G.V. Chernenko, V.M. Fetisov, Technology and Economics of Service 4, 81-82 (2011)

10. K.A. Adigamov, Scientific research: from theory to practice, 176-179 (2016) 
11. K.A. Adigamov, S.S. Petrenko, G.V. Chernenko, Modern Problems of Science and Education 4 (2013)

12. K.A. Adigamov, G.V. Chernenko, A.V. Zelenschikov, Fundamental and applied problems of technics and technology 6-2 (290), 36 - 40 (2011)

13. S.N. Baybara, R.I. Cherkasov, Agro-industrial complex: state, problems, prospects (Penza, 2015)

14. K.A. Adigamov, R.I. Cherkasov, S.N. Baybara, Screw mixer of bulk materials, Invention patent $R F, 2616709,2016115458$ (2017) 